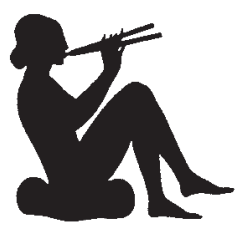

\title{
El repte de la qualitat científica de les revistes d'història de l'art i el seu reconeixement
}

$\mathrm{E}$ 1 mes d'abril de 1996 es va publicar el primer volum de la revista científica d'història de l'art LOCVs AMOENVS, que arriba ara al desè volum $\mathrm{i}$ que ha consolidat la seva trajectòria i la seva periodicitat bianual. En aquests anys ha obtingut un volum d'intercanvis amb altres publicacions prou significatiu en el nombre - cent cinquanta - i en la qualitat, on destaquen museus $\mathrm{i}$ altres institucions universitàries $\mathrm{i}$ acadèmiques de prestigi internacional. A tall d'exemple, entre les estrangeres destaquen la Bibliothèque Nationale de France, la Library of Congress, el Warburg Institute, la University of California Library, el Harvard University Center for Italian Renaissance at Villa I Tatti, el Kunsthistorischen Institut in Florenz, la National Gallery de Londres, el Metropolitan Museum of Art de Nova York, el Rijksmuseum d'Amsterdam, el Musée du Louvre, el Staatlichen Kunstsammlungen de Dresde, la Staatliche Kunsthalle de Karlsruhe o el Schweizerisches Nationalmuseum de Zuric.

LOCVS AMOENVS va ser la primera revista hispànica d'aquesta àrea de coneixement que, a més de l'edició en paper, també es va presentar completa en versió electrònica d'accés obert. L'any 20I0, el total de consultes registrades a RACO era de I4.968 (bttp://www.raco.cat/index.php/Locus/about/consultesI 3 m), mentre que les consultes realitzades per la via del Dipòsit Digital de Documents de la UAB era de I9.I35 (bttp://ddd.uab. cat/accessos/2010/locus/consultes/). I aquest nombre tendeix a augmentar a mesura que la revista és més coneguda i citada i el mateix progrés editorial ofereix cada cop més materials de consulta disponibles. L'acceptació i la utilitat que evidencia aquesta quantitat de consultes no ens eximeix d'aprofundir en la millora de la seva qualitat científica i del seu reconeixement. En aquesta línia, el comitè editor, d'acord amb la política de publicacions 
científiques de la UAB, ha acordat implementar el sistema OJS (Open Journal System) en el procés editorial a partir del pròxim numero. Aquesta aplicació informàtica garanteix, per la seva pròpia estructura de funcionament, el caràcter estable i obligatori del mecanisme de revisió crítica dels treballs presentats, que és un dels indicis de qualitat més valorat per les agències de qualificació de les revistes científiques.

Les bases de dades de sumaris (Dialnet, Latindex, Sumaris CBUC, Ulrich's i Bibliography of the History of Art) i els principals catàlegs col-lectius: OPAC (Regne Unit), SUDOC (França), ZDB (Alemanya) i ISOC (Espanya), recullen les dades de LOCVS AMOENVS. La revista ha estat reconeguda i valorada a diversos índexs: ERIH (European Reference Index for the Humanities), CARHUS Plus, que segueix quasi literalment l'anterior, i RESH (Revistas Españolas de Ciencias Sociales y Humanas), on el 2004 (darrera dada disponible) era la quarta revista en índex d'impacte sobre dinou de valorades (bttp:// resh.cindoc.csic.es/indicedecitas2004.php?varea $=I 5)$. A l'ERIH, la valoració obtinguda per LOCVS AMOENVS és encara baixa (una $\mathrm{C}$ en una escala de qualitat de $\mathrm{A}$ a $\mathrm{D}$ ), però en aquest índex -fortament condicionat per la tradició acadèmica anglosaxona-, en el camp de la història de l'art, només Archivo Español de Arte (fundada el i925) obté una A, mentre que la resta de revistes espanyoles - si surten - no passen d'una $B$ o una C. Compartim plenament el pronunciament dels membres del RIHA (International Association of Research Institutes in the History of Art), del 7 de novembre de 2009 (bttp://www. riba-institutes.org/), contra els poc transparents sistemes de qualificació i de treball de l'European Science Foundation en l'elaboració de l'European Reference Index for the Humanities.

La història de l'art s'ocupa d'un llenguatge obert i universal com és el de la imatge, i també metodològicament és cada cop més permeable i transversal respecte d'altres disciplines properes dins les humanitats. Aquesta universalitat i versatilitat no es contradiuen, però, amb el fet que sovint el seu camp d'estudi i aplicació s'adreci a problemàtiques patrimonials de caràcter local, que en la nostra tradició científica s'orienten lògicament cap a l'art i la cultura catalana o hispànica. Aquesta circumstància evident i comuna fa que la publicació de les nostres recerques en revistes científiques estrangeres només tingui sentit en molt poques ocasions. Els editors internacionals rebutgen aquestes aportacions, no per la seva qualitat, sinó per l'allunyament temàtic respecte dels seus interessos, també relacionats amb les seves tradicions patrimonials. Creure que una aportació obté garantia de qualitat només pel fet que ha estat publicada en una revista estrangera és altament ingenu, però valorar negativament un treball pel fet d'haver estat publicat en una revista hispànica, llevat d'Archivo Español del Arte, creiem sincerament que és ja un absolut despropòsit.

Certament hem de millorar els procediments de gestió i de transparència de les nostres revistes científiques d'història de l'art 
per tal que progressin en els índexs de valoració internacional, però no podem acceptar de forma acrítica com a única guia de qualitat la valoració que ens imposen aquests índexs concebuts i gestionats des d'altres models culturals i acadèmics escassament sensibles a les nostres tradicions científiques. És especialment sagnant constatar que CARHUS Plus, promogut per la Generalitat de Catalunya, s'ha limitat a reproduir les valoracions establertes per l'ERIH i no ha realitzat una tasca real de valoració detallada de les revistes hispàniques. Només ha acceptat una sobrevaloració de les revistes de catalanística sense pensar que altres disciplines, com ara la història de l'art, es troben també dins una problemàtica similar. 